\title{
An unusual cause for neck swelling: apical lung hernia
}

\author{
Srikanth Prasad, Karthik Rao, Jayaprakash Belle, N R Rau
}

Department of Internal Medicine, Kasturba Medical College, Manipal, Karnataka, India

\section{Correspondence to}

Dr Srikanth Prasad, srikanthprasadrao@yahoo.com

\section{DESCRIPTION}

A 50-year-old woman with a history of pulmonary tuberculosis 20 years ago presented to us with cough with copious expectoration and a swelling in the right side of neck which increased on coughing since 2 months. Her physical examination revealed rales in the left interscapular and infrascapular

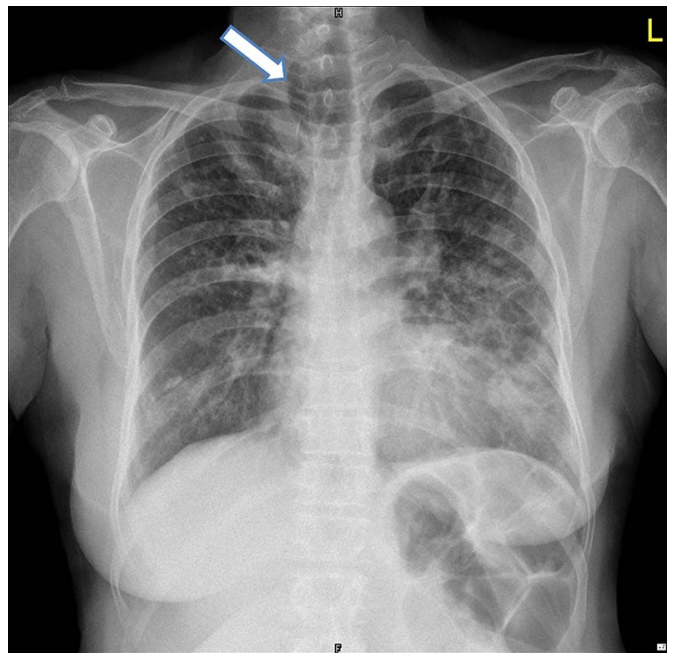

Figure 1 Chest radiograph posteroanterior view showing bronchiectatic changes in the left mid-zone and lower zones and right mid-zone and a radiolucent shadow (marked by arrow) pushing the trachea to the left. areas. Her routine blood workup was normal. Her chest radiograph showed bronchiectatic changes in the left mid-zone and lower zones and right mid-zone and a radiolucent shadow (marked by arrow) pushing the trachea to the left (figure 1). CT of the chest showed a right apical lung hernia (figures 2 and 3). She was diagnosed as a case of post-tubercular bronchiectasis with right apical lung hernia.

Lung hernias can be divided into apical hernia, intercostal hernia and diaphragmatic hernia. Each of them can be subdivided into congenital and acquired varieties. Apical lung hernia is a rare variety and has been confined to few case reports and series. Herniation occurs through a defect in the Sibson's fascia and the apical segment of the lung protrudes in between the scalenus anterior and sternocleidomastoid muscles. In our patient, this defect may be attributed to her chronic cough resulting in tearing of the Sibson's fascia. It is generally asymptomatic except for a swelling in the neck during coughing and Valsalva manoeuver. ${ }^{1}$ It can be diagnosed on posteroanterior and lateral chest radiographs but CT of the chest provides a confirmatory diagnosis. Surgical treatment is rarely warranted unless it undergoes incarceration. ${ }^{2}$ It may cause problems during insertion of internal jugular or subclavian catheters and may result in an inadvertent pneumothorax if a vigilant eye is not maintained.
To cite: Prasad S, Rao K, Belle J, et al. BMJ Case Rep Published online: [please include Day Month Year] doi:10.1136/bcr-2013202952

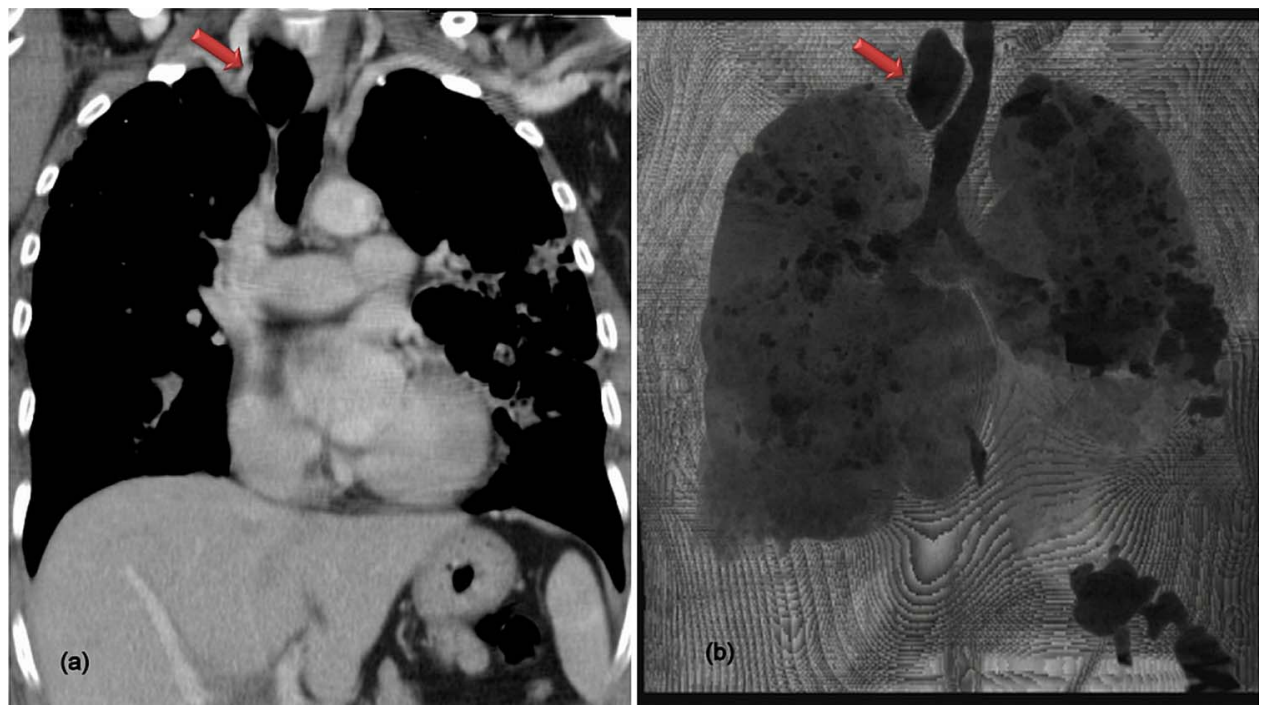

Figure 2 Coronal section of contrast-enhanced CT thorax showing right apical lung herniation (marked with arrow). 


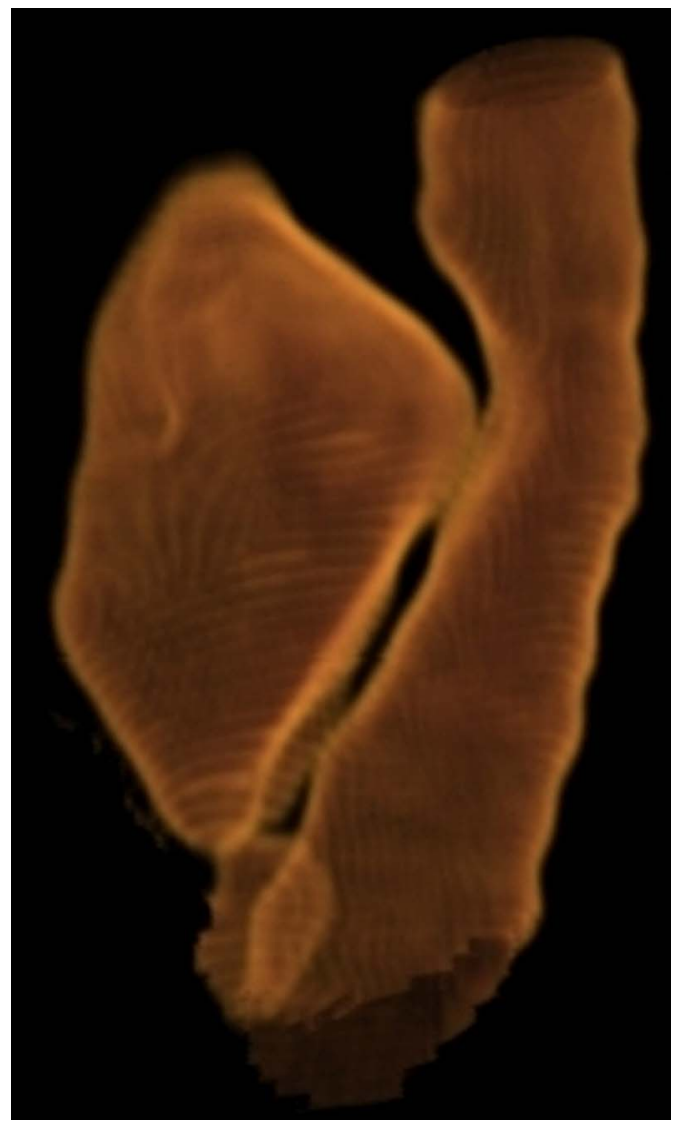

- Apical lung hernia though a rare entity should be considered in the differential diagnosis of a neck swelling.

- Diagnosis is established by chest radiograph and CT imaging.

- One should have a vigilant eye during central venous catheterisation in these patients to avoid inadvertent complications.

Contributors SP and KR were involved in the conception, design, acquisition of the images and drafting of the manuscript. JB and NR were involved in revising it critically for important intellectual content. NR was involved in the final approval of the version published.

Competing interests None.

Patient consent Obtained.

Provenance and peer review Not commissioned; externally peer reviewed.

\section{REFERENCES}

1 Glenn C, Bonekat W, Cua A, et al. Lung hernia. Am J Emerg Med 1997:260-2.

2 Goodman HI. Hernia of the lung. J Thorac Surg 1933;2:368-79.

Figure 3 Three-dimensional reconstructed image showing the herniated right apical lung segment displacing the trachea to the left.

Copyright 2014 BMJ Publishing Group. All rights reserved. For permission to reuse any of this content visit http://group.bmj.com/group/rights-licensing/permissions.

BMJ Case Report Fellows may re-use this article for personal use and teaching without any further permission.

Become a Fellow of BMJ Case Reports today and you can:

- Submit as many cases as you like

- Enjoy fast sympathetic peer review and rapid publication of accepted articles

- Access all the published articles

- Re-use any of the published material for personal use and teaching without further permission

For information on Institutional Fellowships contact consortiasales@bmjgroup.com

Visit casereports.bmj.com for more articles like this and to become a Fellow 